\title{
Interações sociais em ambientes digitais: um estudo sobre blogs de moda a partir de Goffman
}

\author{
Olga Bon \\ Mestre em Comunicação Social pela \\ Pontifícia Universidade Católica do \\ Rio de Janeiro, onde desenvolveu \\ uma pesquisa como bolsista CAPES \\ analisando as atuais formas de \\ comunicação de moda na web, com \\ enfoque nos blogs de moda, suas \\ formas de sociabilidade, mediação \\ cultural e interação social. \\ E-mail: olga.bon.olga@gmail.com
}

Resumo: Este artigo pretende abordar algumas dinâmicas de interação social existentes em ambientes digitais a partir da análise de uma ferramenta midiática específica: os blogs de moda. Páginas virtuais com esse perfil ganharam expressividade, proporcionando o desenvolvimento de uma dinâmica interacional relevante e despertando muitos comentários com os mais diversos objetivos. Essa expressividade contribuiu para que blogs de moda com audiências ativas e numerosas ganhassem relevância no campo da moda, indicando o poder dessas mídias na atualidade. Nesse sentido, novas agentes sociais surgem - as blogueiras de moda -, motivando dinâmicas interacionais específicas. Para compreender essa dinâmica, serão usados alguns conceitos e estudos desenvolvidos pelo autor canadense Erving Goffman.

Palavras-chave: Blogs de moda; Ambientes digitais; Interação social; Erving Goffman.

Title: Social interactions in digital environments: a study on fashion blogs based on Goffman

Abstract: The article intends to address some social interaction dynamics that exists in digital environments, from the analysis of a specific media tool: fashion blogs. Web pages with this profile won expressiveness, allowing the development of relevant interational dynamics, arousing several comments with the most diverse goals. This expressiveness contributed to fashion blogs - with active and numerous visitors - gain relevance in the fashion field, even outside the web, indicating the power of these media nowadays. In this sense, new social actors emerge - the fashion female bloggers - motivating specific and interactive dynamics. To understand this dynamics, we used some concepts and studies developed by the Canadian author Erving Goffman.

Keywords: Fashion blogs; Digital environments; Social interaction; Erving Goffman. 


\section{Introdução}

Este artigo pretende compreender os processos de interação social existentes em alguns blogs de moda a partir da análise das complexidades existentes nessas plataformas midiáticas, que vêm construindo práticas específicas de veiculação de conteúdos relacionados ao universo da moda e áreas afins. A centralidade dessas práticas encontra-se na figura forte e cativa da blogueira, agente direta desse processo.

Como breve explicação do objeto, é interessante dizer que blogs com essas características se disseminaram com notável rapidez, atraindo não só olhares curiosos de amadores, mas também de profissionais do meio fashion que têm se voltado para essa plataforma em busca de oportunidades mercadológicas. Nesse sentido, os blogs de moda vêm construindo um caminho complexo, tornando seu estudo algo importante para a área da comunicação atual. Essas páginas passam a agregar símbolos de consumo e bens materiais, além de representações e mediações culturais.

${ }^{1}$ Sucesso midiático e financeiro.

${ }^{2}$ Em matéria na revista Veja, de abril de 2013, já se estimava que blogueiras de moda famosas tivessem um lucro mensal de R\$ 100.000,00 (HONORATO, 2013).
Seguindo essa direção, pode-se notar a forma como os principais blogs de moda de sucesso ${ }^{1}$ vêm se profissionalizando e se posicionando no universo da moda, fazendo que a ideia inicial de um blog como plataforma simplificada e informal seja abandonada, assumindo características de grandes espaços publicitários e arenas de disputa de poder. Com isso, blogs de moda bem-sucedidos - financeira e midiaticamente - vêm sendo transformados em fontes de renda bastante lucrativas $^{2}$ e em novos tipos de negócio, tornando-se aparatos midiáticos complexos que exercem influência no mercado e nos processos comunicacionais do campo da moda.

Com alto poder de mediação, esses blogs são capazes de motivar uma audiência volumosa e centenas de comentários, gerando diferentes tipos de interações sociais dentro de um ambiente digital específico. Nesse sentido, as contribuições e conceitos do autor canadense Erving Goffman, conhecido por seus estudos de processos interacionais, se apresentaram como eficientes meios teóricos para a compreensão dessas interações identificadas dentro da dinâmica dos blogs estudados. Seu conceito de face-work e suas vertentes serão utilizados ao longo do trabalho por meio da utilização de dados coletados dos blogs Super Vaidosa, de Camila Coelho, Blogueira Shame e das páginas do Instagram: Babadeira, Garotas Estúpidas e Helô Gomes. Todas as páginas apresentadas e estudadas foram recortadas a partir das necessidades que a pesquisa trouxe. Como aqui nos interessa os processos interacionais, páginas com audiências ativas e volumosas se mostraram mais adequadas e em concordância com os objetivos do estudo. Por isso as blogueiras citadas acima foram escolhidas. Em relação à exposição dos dados, é necessário dizer que a identidade das leitoras aqui expostas foi preservada, assim como os nomes e fotos das blogueiras famosas foram mantidos, por serem personas conhecidas e figuras públicas.

A metodologia baseou-se, majoritariamente, na análise textual dos comentários coletados e aqui explicitados, por entender-se que essa escolha metodológica seria eficiente e objetiva na ilustração dos conceitos elaborados por Goffman. Dessa maneira, foram apresentados exemplos reais e concretos provenientes do objeto, a fim de compreender de forma mais eficiente os estudos do autor. Goffman buscou estudar, entre outras coisas, processos de ordem interacional que buscam iniciar ou encerrar uma conversa, a manutenção das aparências, determinadas maneiras de falar e se expressar etc., afastando-se de análises estritamente ligadas a fatores psicológicos ou apenas emocionais. Atribuindo significativa importância à experiência social, o sociólogo entendeu a interação como um processo fundamental de identificação e diferenciação dos indivíduos, no qual o mundo passa a ser visto, metaforicamente, como um grande teatro, e nós, tanto individual quanto coletivamente, teatralizamos diferentes ações e 
rituais. Desse modo, não foi o objetivo deste artigo pensar as motivações internas e profundas para a realização de cada comentário exposto, visto que o próprio Goffman se distanciou de análises desse tipo nas obras utilizadas para a realização do trabalho apresentado.

\section{Dramaticidade e interações sociais em blogs de moda}

Erving Goffman, em seu clássico A representação do Eu na vida cotidiana (1996) e em Ritual de interação - ensaios sobre o comportamento face a face (2012) aborda de forma detalhada as interações sociais entre os indivíduos e as relações cotidianas. Alguns de seus conceitos serão explorados neste artigo, pois servem de pano de fundo para descrever algumas situações provenientes da interação social existente em certos blogs de moda. Portanto, é mais interessante, nesse momento, analisar a interação social do fenômeno estudado, justamente por esse fenômeno formar um "sistema social mantido através da interação" (GOFFMAN, 2012, p. 12) e ser gerador de múltiplas atividades.

Para Goffman, a informação sobre o indivíduo possibilita o conhecimento prévio do que se pode esperar dele, assim como o que ele espera dos demais. No jogo da interação estudado pelo sociólogo canadense, o indivíduo expressa a si mesmo, ao mesmo tempo que impressiona os observadores. Para o autor, o indivíduo é capaz de influenciar - mas não de definir totalmente - o modo com que os outros o perceberão pelas suas ações, e por vezes tentará manejar a impressão causada no outro por meio de "apresentações do self, onde são veiculadas representações de identidade e de individualidade" (BRAGA, 2007, p. 8). Fazendo um gerenciamento da imagem será possível haver uma orientação a respeito das consequências de determinada interação.

Os materiais comportamentais definitivos são as olhadelas, gestos, posicionamentos e enunciados verbais que as pessoas continuamente inserem na situação, intencionalmente ou não. Eles são os sinais externos de orientação e envolvimento - estados mentais e corporais que não costumam ser examinados em relação à sua organização social (GOFFMAN, 2012, p. 9).

Dessa forma, "a apresentação do self - como na formulação goffmaniana - regula e organiza a interação ali decorrente" (BRAGA, 2007, p. 8). Mas, por mais que o indivíduo possa tentar manejar a impressão provocada com estratégias para manipular uma impressão positiva, lançando mão de diferentes recursos, a compreensão por parte do observador pode estar de acordo com a intencionalidade proposta pelo indivíduo ou não. Para o autor, grande parte do comportamento cotidiano é semelhante ao de atores no palco, já que indivíduos e grupos estão constantemente representando uns para os outros e gerenciando a apresentação de seu self.

Para Goffman (1996), a informação que temos um do outro serve para definir a situação, a fim de se alinhar de modo "adequado" aos diferentes ambientes, posturas e situações. Segundo o autor:

Quer um ator honesto deseje transmitir a verdade ou quer um desonesto deseje transmitir uma falsidade, ambos devem tomar cuidado para animar seus desempenhos com expressões apropriadas, excluir expressões que possam desacreditar a impressão que está sendo alimentada e tomar cuidado para evitar que a platéia atribua significados não-premeditados (p. 67).

Ainda segundo Goffman, no palco, um ator se apresenta sob a máscara de um personagem para personagens projetados por outros atores. Já a plateia constitui outro elemento essencial para essa correlação, ambos desempenhando papéis. 
${ }^{3}$ Para a realização deste trabalho, a autora baseou-se no livro Ritual de interação - ensaios sobre o comportamento face a face. Essa tradução utilizou o termo "fachada" no lugar de "face", apresentando a seguinte nota: "Em português não utilizamos este termo (face, no inglês) com a conotação que Goffman empresta aqui [...] É um termo de tradução particularmente complicada, porque, como veremos no decorrer do texto, ele é usado em contextos variados com significados variados. Quando isto ocorrer, o termo original será assinalado no texto [N.T.].". Por entender que o conceito de fachada se diferencia do conceito de face, a autora optou por manter os termos originais ao longo do artigo. Em relação à expressão face-work, cunhada por Goffman, será usado o termo "trabalho de face", já amplamente utilizado pela linguística, sociologia e áreas afins. Em citações diretas, o termo "fachada" estará presente devido à tradução na qual foram retirados os trechos apresentados.

${ }^{4}$ Blogueira Shame é um blog que realiza postagens irônicas e sarcásticas em relação aos blogs de moda, famosos ou desconhecidos. Nessas postagens, erros de escrita e ortografia são apontados, bem como denúncias em relação a plágios, publicidade velada ou situações semelhantes. Endereço completo: www.blogueirashame.com.br.
Outro conceito de Goffman (2012) que nos serve com bastante perspicácia no momento é o conceito de face ${ }^{3}$.

\begin{abstract}
O termo fachada (grifo no original) pode ser definido como o valor social positivo que uma pessoa efetivamente reivindica para si mesma através da linha que os outros pressupõem que ela assumiu durante um contato particular. A fachada é uma imagem do eu delineada em termos de atributos sociais aprovados mesmo que essa imagem possa ser compartilhada, como ocorre quando uma pessoa faz uma boa demonstração de sua profissão ou religião ao fazer uma boa demonstração de si mesma (p. 13).
\end{abstract}

Dessa forma, modos de vestir e demonstrar socialmente certos estilos de vida, mesmo que não sejam condizentes com o eu daquele indivíduo em sua intimidade, fazem parte desse automonitoramento e do trabalho de face (face-work), que pode ser entendido como ações que o indivíduo realiza a fim de tornar o que quer que esteja fazendo consistente com sua imagem construída. É preciso que o indivíduo trabalhe esses itens continuamente para que o jogo da dramaticidade se sustente.

Para ilustrar alguns conceitos mencionados até aqui, serão apresentadas situações que ocorreram com a blogueira Camila Coelho, do blog Super Vaidosa. Camila é bastante conhecida e tem forte apelo midiático. Seu blog atinge marcas surpreendentes de audiência, com centenas de comentários a cada postagem. Atualmente, a blogueira participa de vários projetos publicitários com grandes marcas e empresas, incluindo comerciais na TV aberta. Camila Coelho teve uma foto publicada no Blogueira Shame ${ }^{4}$ na qual usava uma blusa ainda com a etiqueta presa e localizada na parte de trás, durante a gravação de um vídeo no qual ensinava dicas de maquiagem. Devido ao fato, Camila recebeu dezenas de críticas e comentários sobre sua "falsidade", sendo acusada de usar roupas emprestadas como forma de propaganda para a marca presente na etiqueta em questão. Podemos dizer então que o trabalho de face de Camila ficou prejudicado no momento do episódio.

A blogueira também foi alvo de outra polêmica, quando foi acusada de mentir novamente sobre uma propaganda de gel dental que indicou para suas leitoras em um vídeo, dizendo que estava dando uma "dica de amiga". Dessa vez, a situação foi mostrada pela página do Instagram Babadeira, especializada em fofocas de celebridades. A seguir podemos ver a foto postada pela página, com a cópia da justificativa que Camila havia dado em seu blog, seguida por um detalhamento da denúncia; uma espécie de passo-a-passo com o objetivo de "desmascarar" a blogueira:

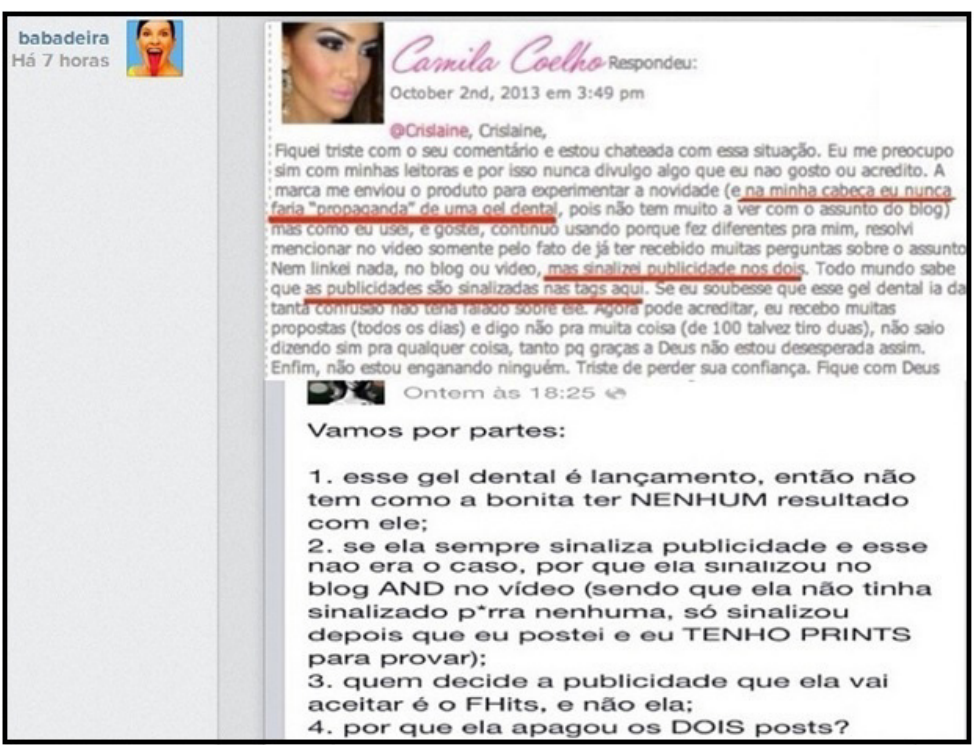

Figura 1: Instagram Babadeira, outubro de 2013 
${ }^{5}$ Esse número corresponde à última análise feita na página do Facebook de Camila Coelho, em 03 de outubro de 2015.
A tentativa de se autojustificar observada em Camila Coelho poderia ter sido motivada pela sua percepção de que algo havia acontecido com sua imagem pública, sentindo-se assim constrangida pelo ocorrido, pois, segundo Goffman, em situações semelhantes, uma pessoa pode se sentir envergonhada (shamedface) (GOFFMAN, 2012). O fato de Camila tentar se justificar ou afirmar que sinalizou propaganda nos vídeos e que "não está enganando ninguém" - em suas palavras - insinua uma tentativa de preservação de sua imagem, ou seja, o trabalho para mantê-la o mais condizente possível com a construção que a blogueira realizou até o acontecimento relatado. É interessante notar que mesmo com todas essas polêmicas, o blog de Camila continuou tendo publicações regulares, com 2.594.180 "curtidas" atuais em sua página oficial do Facebook, e a imagem da blogueira continua sendo explorada de forma crescente por publicidades, campanhas e parcerias com grandes empresas.

O ocorrido com Camila Coelho movimentou outras páginas na internet, como o Instagram Babadeira e o Blogueira Shame, e aumentou o número de comentários no próprio blog de Coelho, devido ao interesse nas polêmicas em que a blogueira se viu envolvida. Mas os episódios não representaram uma queda significativa e definitiva em sua audiência. Isso apontou uma ruptura abrupta e passageira na dinâmica do blog, mas que não altera sua rotina de forma profunda. Para Goffman, "algumas ocasiões de constrangimento parecem ter um caráter orgástico abrupto; uma introdução repentina do evento perturbador é sucedida por um pico imediato na experiência do constrangimento e então por um retorno lento à tranquilidade anterior" (GOFFMAN, 2012, p. 98).

Porém, por causa do aspecto lento desse retorno à tranquilidade, muitas manifestações contrárias à blogueira puderam ser percebidas no espaço destinado aos comentários, seja no blog de Camila ou em outras páginas, enquanto o retorno à dinâmica rotineira do blog não se fez presente de forma completa. $\mathrm{Na}$ maioria das vezes, situações como a do gel dental, por exemplo, geram conflitos e decepção por parte do público, que se sente enganado e chega a falar que nunca mais vai acreditar em nada que a blogueira disser. Essa situação pode ser descrita como to lose face: "Em nossa sociedade anglo-americana, assim como em algumas outras, a expressão "perder a fachada" (to lose face) parece significar estar com a fachada errada, estar fora de fachada, ou estar com a fachada envergonhada" (GOFFMAN, 2012, p. 13).

É interessante observar que quando ocorrem fatos como os descritos anteriormente - do gel dental e da etiqueta - muitas leitoras se unem para tentar desvendar outras possíveis mentiras e farsas, trabalhando o tempo todo sob o conflito da autenticidade e da fidedignidade. Elas correm atrás de vídeos já apagados que poderiam servir como provas, negociam sentidos e revelam a insatisfação de se sentirem enganadas, como nos exemplos aqui apresentados.

Nessa série de comentários, é possível observar a ideia de Goffman (to lose face), que conhecemos aqui mais por expressões informais como "a cara caiu" ou "a cara foi ao chão", que tem a ver com outra expressão popular bastante conhecida: "cara de pau". Essa expressão serve para caracterizar situações em que a pessoa não age de acordo com o bom senso ou com o que é esperado dela, muitas vezes causando constrangimento para ela mesma e para os outros envolvidos na interação. Desse modo, o constrangimento não está localizado no indivíduo, mas no sistema social. No Blogueira Shame, por exemplo, há uma seção chamada "woodface do dia" ${ }^{6}$, que relata situações de blogueiras diversas que estejam trabalhando dentro de uma lógica que pode ser considerada "cara de pau". No exemplo anterior, há um comentário de uma leitora que diz: "já é candidata para o woodface do ano" - isso ilustra como as leitoras reagem ou podem reagir ao depararem com situações semelhantes, ao se sentirem enganadas e "passadas para trás" por uma persona com uma carreira que depende de leitores e fãs para aumentar sua credibilidade e legitimar seus 
conteúdos, e que hoje seria capaz de mentir e de "perder a fachada" por questões financeiras e publicitárias. A blogueira, de acordo com a lógica das leitoras, não honrou com seu eu projetado pelas participantes daquele sistema social, e falhou em seu próprio trabalho de face.

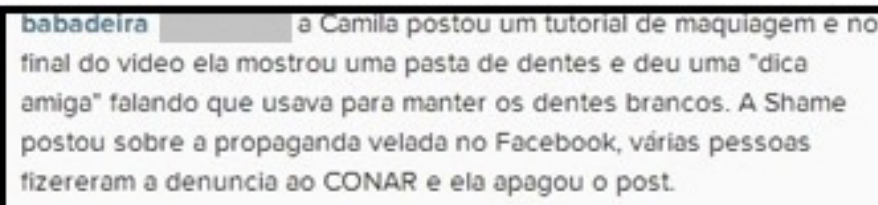

Eu quando descobri ela no começo,|só tinha 6 vídeos

no canal dela),eu gostava dela,mas depois ela mudou muito,ficou

muito metida,ainda q ela diga q ñ̀,hoje em dia vejo um video novo e nem ligo pra ver,antes ficava antena e ñ perdia um vídeo. Fica

querendo abraçar tudo de uma vez (ñ digo q esteja errada), mas $90 \%$

do q ela fala em vídeos,eu ñ acredito e sei q é publicidade.

Muito fail a justificativa de Comile para a leitora. Pense q engane quem?? $\square \square \square \square$

Olha o video que ela tirou do ar:

http://youtu.be/ib7xV58mK E

\section{A Bunny é a mais mentirosa de TODAS!"}

\section{Assisti o vídeo ! Nossa que cara d}

pau! Daí dps a loka começa a falar da Make de novo como se nada tivesse acontecido... Por mais que pudesse ser dica mesmo... Ficou forçado demais, e ela $n$ entendeu ainda que ninguém acredita mais nas dicas dela.

seró que depois desso elo aprendeu

o liçāo? Duvido muito...

A Titia postou o print da pastagem dela sem sibalizar a propaganda. Eu ri demais. A Bunny se faz de coitada pra depois a Titie desmascarar kkkkkkk muito otarie. Já é candidate pra o woodface do ano.

comentário de vcs... Eu nem conhecio o Comila oté elo ganhar o capo do revisto ló, mos ocho elo froquinho demais.. Sei ló... Metidinho... Outro dia vi umo foto dela no aeroporto e elo colocou: indo pro minho segunda caso, alguém adivinha? E elo fol pra Paris, veio uma moça e talou: achei q sua segunda casa tosse o Brasil.. Kkkkkk.. Pols é né??

Antes do Brasil tem "tantas" casas pra ela... Afttt

$$
\text { vc está tirando com a minha face! }
$$

Kkkkkkkk. É sério isso, produçăo?! Mas năo foi a primeira vez que ela toi pra Paris? Attrtt1... Que mina ridicula!!!

Figura 2: Instagram Babadeira, outubro de 2013

Nota-se que a defesa também se faz presente nesse tipo de situação. Essa defesa pode partir das próprias leitoras, como observado no próximo exemplo: 


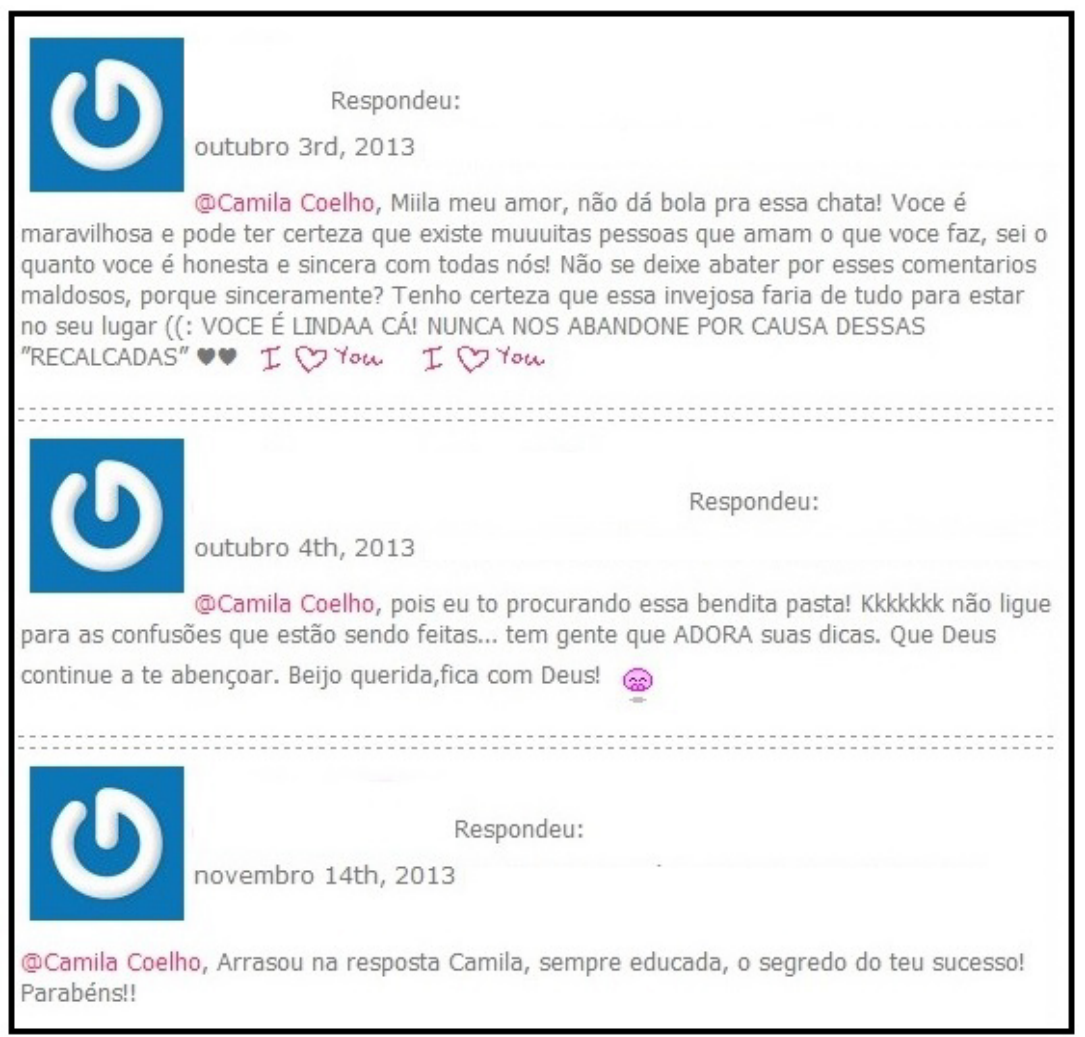

Figura 3: Blog Super Vaidosa, outubro de 2013

Percebe-se que as leitoras defendem Camila de acusações que, segundo elas, seriam sem fundamento e motivadas por sentimentos negativos, como a inveja. Segundo essas leitoras, o erro não teria partido de Camila Coelho, mas uma "confusão" havia sido feita. Nota-se também que as leitoras aproveitam o espaço de defesa para elogiar a blogueira. Sob a ótica goffmaniana, isso ocorre porque a pessoa:

pode querer salvar a fachada dos outros por causa de sua ligação emocional com uma imagem deles, ou porque ela sente que seus coparticipantes têm um direito moral a esta proteção, ou porque ela quer evitar a hostilidade que poderá ser dirigida para ela se eles perderem sua fachada (GOFFMAN, 2012, p. 20).

A partir dos elogios dirigidos a Camila, nota-se que a defesa das leitoras é motivada, entre outros fatores, por uma ligação emocional que elas criaram com a imagem da blogueira, que alcançou um patamar midiático significativo, o que pode ter ajudado no desenvolvimento dessa ligação emocional muito semelhante ao que vemos na relação fã-celebridade. Uma leitora, como mostra a Figura 3, começou seu "comentário-defesa" com a frase: "Mila, meu amor". Ou seja, além de ser carinhosa, ainda chamou a blogueira por um apelido íntimo, apesar de não conhecê-la na esfera privada. Outro comentário nos mostra que a leitora estava procurando a "bendita pasta", fazendo referência ao gel dental que iniciou a "confusão", sem se importar com a polêmica gerada em torno do caso, ratificando a importância atribuída à opinião da blogueira, que indicou o uso do produto. De acordo com Goffman, quando o trabalho de face é ameaçado e sua preservação se faz necessária, não importa muito se essa preservação parte da própria pessoa ou se é feita por uma testemunha do ocorrido. Camila Coelho respondeu às críticas relacionadas ao gel dental naquele extenso comentário exposto anteriormente, e depois somente as leitoras fizeram sua defesa. A blogueira não se manifestou mais, evidenciando um dos tipos básicos de preservação do trabalho de face apresentado por Goffman, o processo de evitação: "a saída mais garantida para uma pessoa evitar ameaças à sua fachada é evitar contatos em que seria provável que essas ameaças ocorressem" (GOFFMAN, 2012, p. 67). É significativo perceber 
que esse processo se torna mais difícil e delicado na internet, pois mesmo que Camila Coelho tenha optado por apagar o vídeo que causou toda a polêmica em questão, as próprias participantes e leitoras já tinham salvado-o e compartilhado entre si, como pudemos ver nos comentários apresentados.

No caso relatado envolvendo Camila Coelho, a blogueira tentou não se envolver mais após escrever um esclarecimento, deixando que suas próprias leitoras partissem em sua defesa diante do ocorrido. Porém, em outras situações envolvendo blogueiras famosas, como Camila Coutinho, comentários de defesa com diferentes teores podem ser identificados e caracterizados de formas distintas:

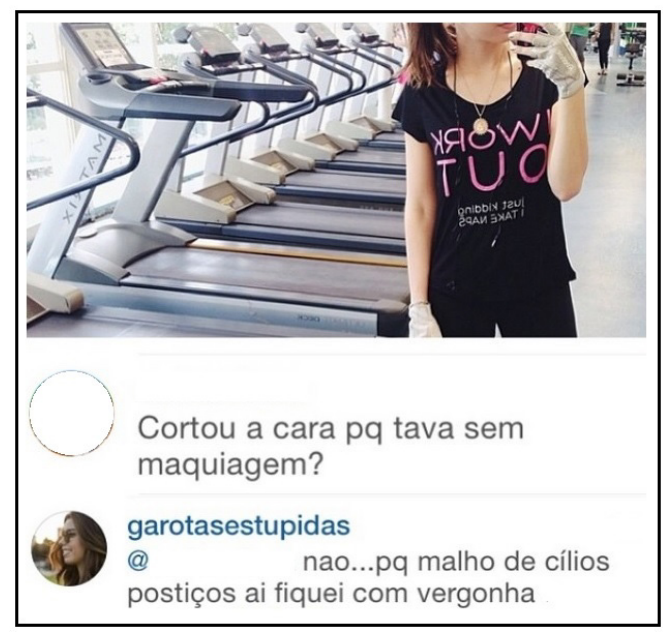

Figura 4: Instagram de Camila Coutinho, do blog Garotas Estúpidas, maio de 2014

Na Figura 4 é possível identificar um exemplo em que Camila Coutinho, do blog Garotas Estúpidas ${ }^{7}$, responde ao comentário de uma leitora em tom provocativo. A leitora pergunta: "cortou a cara pq tava sem maquiagem?", referindo-se ao fato de Coutinho ter postado uma foto em seu Instagram pessoal, na academia, e ter optado por não colocar o rosto. A blogueira, por sua vez, responde com outro comentário, em tom de ironia: "não... pq malho de cílios postiços ai fiquei com vergonha". Esse comentário seria o que Goffman chamaria de "alfinetada", que funciona através da

${ }^{7} \mathrm{O}$ blog de moda Garotas Estúpidas também é bastante conhecido em esfera nacional e internacional. Sua audiência chega a 8 milhões de visitas por mês. alusão a uma tentativa de resgate da respeitabilidade moral de quem o faz. Outra forma de lidar com situações semelhantes, observada por Goffman, é aquela de teor "esnobe", também encontrada em comentários provenientes de blogueiras de moda e de suas leitoras e/ou participantes daquele ambiente, como mostra o exemplo a seguir, que ocorreu com Helô Gomes, do blog Sanduíche de Algodão:

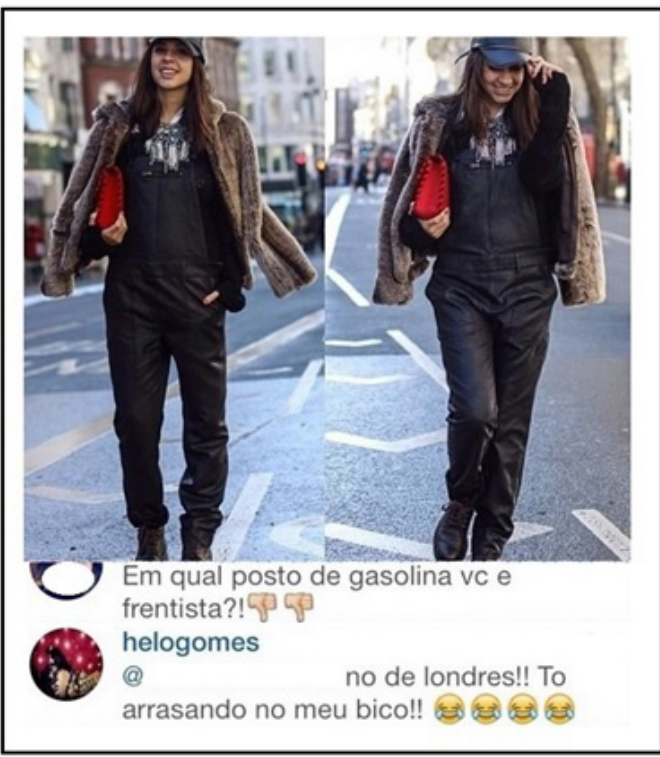

Figura 5: Instagram de Helô Gomes, do blog Sanduíche de Algodão, julho de 2014 
Helô Gomes, em seu Instagram pessoal, respondeu a uma crítica relacionada ao tipo de vestimenta escolhida por ela, que foi comparada ao uniforme usado por frentistas. A blogueira optou por responder de forma irônica ao comentário, dizendo que estava fazendo um "bico" em um posto na cidade de Londres. Dessa maneira, Gomes fez alusão a um destino turístico mundialmente conhecido, e que requer certa condição financeira para conhecê-lo. Assim, Helô Gomes, a partir do seu comentário em resposta à crítica, fez alusão a sua posição de classe social privilegiada. Tanto o comentário de teor "esnobe", quanto o de "alfinetada" são relacionados com o que Goffman chama de "malícia" (GOFFMAN, 2012).

Ainda que a blogueira opte por não fazer nenhum tipo de comentário em resposta às críticas, elogios, ofensas ou ironias, não quer dizer que ela esteja livre de receber qualquer comentário de natureza diferente. A blogueira, dessa forma, recebe diferentes avaliações, que podem ser aceitáveis ou não para ela. Nesse ponto, a dona do blog pode aceitar comentários elogiosos ou críticos, ou simplesmente ignorar ou apagar comentários com teor negativo, não aparecendo para as demais pessoas que visitarem aquele espaço virtual. Também é a partir dos comentários que esse segmento pode perceber se o conteúdo veiculado pelo blog agradou ou foi rejeitado pela maioria. Dessa forma, o olhar direcionado à análise de espaços destinados aos comentários dentro de blogs de moda de sucesso torna-se um campo promissor para descobertas interessantes sobre o fenômeno em questão, principalmente em relação à mediação, interação e dinâmicas de sociabilidade que se desenvolvem ali, replicando-as para outros espaços além do blog.

\section{Conclusão}

Este trabalho se propôs a observar alguns pontos presentes em blogs de moda que têm uma audiência atuante e volumosa no que concerne à interação social proveniente dessas páginas, que acabam gerando conteúdos replicados em outras páginas devido à participação ativa de leitoras nos espaços destinados aos comentários localizados nos blogs e em outras redes sociais.

Ao voltar o olhar para os blogs de moda, passamos a perceber que as agentes diretas desse processo de mediação, as blogueiras, vêm ganhando um status cada vez mais próximo ao de celebridades já conhecidas e reconhecidas pela mídia de massa tradicional, fazendo que esse segmento seja apresentado a um público extenso e diverso. Dessa forma, blogueiras de moda bem-sucedidas passam a transitar de microcelebridades (BRAGA, 2008) para celebridades/personalidades do universo da moda.

Esse cenário contribui para o aumento do apelo midiático desses blogs, fazendo que sejam conhecidos por uma parcela considerável de pessoas. Portanto, as complexidades existentes nas formas de interação social promovidas por esses blogs de moda geram tensões e negociações de sentido próprio. Como forma de análise de alguns pontos presentes no objeto de estudo, foram utilizados conceitos desenvolvidos por Erving Goffman, com o objetivo de compreender alguns fatores que estruturam e motivam a relação entre os indivíduos que compõem os sistemas sociais analisados. Por se tratar de um fenômeno vivo que se desenrola cotidianamente, uma conclusão fechada e inflexível não é o foco deste trabalho. Trata-se, portanto, de uma tentativa de compreensão de algumas formas interacionais que ocorrem nessas páginas.

Em situações presenciais, a compreensibilidade de reconhecimento de constrangimentos ou quaisquer desvios de condutas tidas como normais em um indivíduo é um pouco maior devido à presença física e notável de sinais objetivos, como suor, tremores ou piscadelas. Mas em ambientes digitais, um estudo a respeito desses sinais é ainda mais complexo, pois eles se tornam mais difíceis de serem percebidos e analisados de forma espontânea. Assim, as complexidades 
existentes nas formas de interação social promovidas pelos blogs de moda geram formas muito próprias de observação. Partindo da leitura de Goffman, este artigo buscou apreender alguns processos de interação social dentro dos ambientes digitais voltados ao fenômeno dos blogs de moda de sucesso, ratificando a importância dos espaços destinados aos comentários - principal fonte de observação da análise - para melhor percepção dos processos interacionais presentes em ambientes on-line e digitais.

\section{Referências Bibliográficas}

BABADEIRA. Disponível em: <www.instagram.com/babadeiraoficial $>$. Acesso em: 30 nov. 2015.

BLOGUEIRA SHAME. Disponível em: <www.blogueirashame.com>. Acesso em: 30 nov. 2015.

BOURDIEU, P. A distinção - crítica social do julgamento. Porto Alegre: Zouk, 2007.

BRAGA, A. Ciber-cultura feminina: interação social em um weblog. E-Compós, v. 9, 2007.

. Personas materno-eletrônicas: feminilidade e interação no blog Mothern. Porto Alegre: Sulina, 2008.

GAROTAS ESTÚPIDAS. Disponível em: <www.garotasestupidas.com>. Acesso em: 30 nov. 2015.

GOFFMAN, E. A Representação do Eu na vida cotidiana. Petrópolis: Vozes, 1996.

Ritual de interação - ensaios sobre o comportamento face a face. Petrópolis: Vozes, 2012.

HONORATO, R. Como blogueiras fazem da moda um negócio lucrativo. Revista Veja [on-line], 2013. Disponível em: <http://veja.abril.com.br/noticia/vidadigital/como-blogueiras-fazem-da-moda-um-negocio-lucrativo>. Acesso em: 14 maio 2015.

MEAD, G. H. Mind, self and society. Chicago: University of Chicago Press, 1984.

SANDUÍCHE DE ALGODÃO. Disponível em: <http://www.sanduichedealgodao. com.br/>. Acesso em: 30 nov. 2015. 